\title{
A comparative cross-sectional analysis on prevalence of depression and associated risk factors among medical students and doctors of Karachi, Pakistan
}

\author{
Muhammad Fazal Hussain Qureshi ${ }^{1 *}$ B , Danish Mohammad ${ }^{1}$, Sara Sadiq ${ }^{2}$, Zain Jawed Abubaker ${ }^{1}$, Ujalla Kumari ${ }^{1}$, \\ Joti Devnani ${ }^{1}$, Nakeeta Dawani ${ }^{1}$, Fahad Khalid Soleja ${ }^{1}$ and Ayesha Haroon ${ }^{1}$
}

\begin{abstract}
Background: It has been noted that there is high prevalence of depression among medical personnel whether it is a student or an on-duty doctor. However, no study has been done to highlight these two vulnerable groups. Accordingly, the objective of current study is to compare the prevalence of depression among medical students and doctors working in hospitals, and its correlation with demographic variables, associated symptoms and history of any recent trauma. A descriptive cross-sectional study design was selected for this study. PHQ-9 was used as study tool.

Result: Mean age of students was $21 \pm 1.83$ while the mean age of the doctors included in study was $31 \pm 7.8$. A multivariate analysis model (MANOVA) was applied where male doctor and students were found to have a significantly high association ( $p=<0.001$ ) with depression scores as compared to their counterpart and students. Positive association was observed among sector and symptom of hopelessness, sleep changes and appetite/weight changes. The most common symptom among both groups was sleep changes while the least common symptom among doctors was concentration problem and among students was feeling of helplessness. It was also found that $26 \%$ of the students were having suicidal thoughts while only $16 \%$ of the doctors were having suicidal intentions.

Conclusion: It is concluded that depression is highly prevalent among medical students when comparing with onduty doctors, so they should be screened with regular intervals and good counselling sessions to prepare them for a better health care system.
\end{abstract}

Keywords: Depression, Anxiety, Doctors, Medical students

\section{Background}

Depression is an irritable or sullen state of mind in which there is a lack of interest in routine activities, having sense of either hopelessness or helplessness, anger irritability and anxiety [1]. Looking over the global burden of disease, depression accounts for about $3.2 \%$ of total and is highly prevalent among students as multiple

\footnotetext{
* Correspondence: fazalhqureshi22@gmail.com

'Ziauddin University, 4/B Shahra e Ghalib, Block 6, Clifton, Karachi, Pakistan

Full list of author information is available at the end of the article
}

meta-analysis reported higher prevalence of depression among graduating students when comparing with other students [2]. About 33\% of students have depressive symptoms [3], and noticeably among them, the majority are medical students, consisting of $27-50 \%$ of total [4]. Considering specifically the Pakistan, it is about 34\% among students out of which $43.89 \%$ correspondents are medical students [5] and majority are from Karachi, i.e. $60-70 \%$ [6]. The major factors reported behind the higher prevalence of depression among medical students include study load, professional exams, inability to cope-

\section{Springer Open}

() The Author(s). 2020 Open Access This article is licensed under a Creative Commons Attribution 4.0 International License, which permits use, sharing, adaptation, distribution and reproduction in any medium or format, as long as you give appropriate credit to the original author(s) and the source, provide a link to the Creative Commons licence, and indicate if changes were made. The images or other third party material in this article are included in the article's Creative Commons licence, unless indicated otherwise in a credit line to the material. If material is not included in the article's Creative Commons licence and your intended use is not permitted by statutory regulation or exceeds the permitted use, you will need to obtain permission directly from the copyright holder. To view a copy of this licence, visit http://creativecommons.org/licenses/by/4.0/. 
up the demands, stress, anxiety and lack of psychological support [7]. Educational stress is a leading factor to mental distress that can influence negatively, resulting in cognitive and learning impairment [8].

On the other hand, occupational stress is also one of the major reasons behind depression among different professionals that directly affects the productivity. According to the National Institute of Mental Health (NIMH), around 14.4 million of adult population are annually diagnosed as depressed because of occupational stress [9]. Among different professions, doctors are more vulnerable to develop depressive symptoms because of excessive emotional stress of emergency management, critical decision-making, death declaring, demanding patients, work load, duty hours, night shifts, unintentional medical mistakes and lack of sleep etc [10]. The global prevalence of depression among doctors is $10-15 \%$ [11, 12], while looking over Pakistan, about $25-30 \%$ doctors are facing the depressive symptoms [13].

Literature revealed that the medical field as a whole is a leading cause of developing depression. It has been noted that there is high prevalence of depression among medical personnel whether it is a student or an on-duty doctor. None of the study has been done in South Asia to highlight these two vulnerable groups, and suicide rates are continuously increasing in these groups. The objectives of current study are to compare the prevalence of depression among medical students and doctors working in hospitals, and its correlation with demographic variables, associated symptoms and history of any recent trauma.

\section{Methods}

\section{Characteristics of study}

A descriptive cross-sectional study design was selected for this study. Multistage non-probability consecutive type of sampling technique was used. Sample size was calculated from Openepi and was found to be 384 at 95\% confidence interval with 5\% margin of error. The study was approved by the ethical review board of Ziauddin University and was conducted for a period of 1 year, i.e. January 2019 to December 2019.

\section{Sample selection}

Sample was divided into two broader categories, i.e. medical students and doctors. Students studying in different years of MBBS, from any medical university of Karachi without any diagnosed mental conditions, were included in this study. Doctors working in different hospitals of Karachi, irrespective of their designation (house officers, residents and consultants), without any diagnosed mental disorder were included in this study. Students from other medical specialities, i.e. BDS, Pharmacy and Physiotherapy, were excluded in order to avoid bias on the basis of different study pattern and schedules.

\section{Data collection tool and procedure}

Public Health Questionnaire (PHQ-9), introduced by Pfizer [14], was used for identification of depression along with slight additions regarding demographic information, signs and symptoms, coping mechanisms and risk factors for depression. PHQ-9 scores each of the nine DSM-IV criteria as "0" (not at all) to "3" (nearly every day). Participants having scores between 0 and 4 were labelled as normal, scores between 5 and 9 were labelled as mild, scores between 10 and 14 were labelled as moderate, scores between 15 and 19 were labelled as moderately severe and scores above 20 were labelled as severe. PHQ-9 has $61 \%$ sensitivity and $94 \%$ specificity in adults [15]. Questionnaire was validated on a sample of 30 participants, and co-efficient of reliability was found to be 0.888 . The questionnaire was disseminated personally, and responses were recorded on paper and then coded for analysis.

\section{Data analysis}

Data was analysed using Statistical Package for Social Sciences (SPSS) version 22. Two sectors (doctor and students) were made in order to run comparative analysis. The mean with standard deviation was calculated for quantitative variables while frequency and percentages for qualitative variables. Multivariate analysis model (MANOVA) and chi-square were used to establish associations between depression scores, symptoms and demographic data. $p$ value $<0.05$ was considered as significant.

\section{Results}

Out of 450 forms distributed, 400 completely filled forms were received (response rate $88 \%$ ). Mean age of students was 21 with a standard deviation of 1.83 while the mean age of the doctors included in study was 31 with a standard deviation of 7.8. Female comprises 33\% of the sample population while $67 \%$ of the sample population were male. Relationship status of $70 \%$ of the participant was single followed by married (18\%), committed (11\%) and divorced (1\%). Most common ethnicity was Urdu speaking (38\%) followed by Sindhi (23\%), Punjabi (21\%), Pathan (8\%) and Balochi (1\%), and $9 \%$ of the population belong to other ethnicities.

A multivariate analysis model (MANOVA) was used to analyse the effect of sector and depression scores on demographics as shown in Table 1, and it was found that there was significant difference in age and relationship status as compared with the sector, and when gender and depression scores were analysed, difference was found to be significant. Further multiple ANOVAs were 
Table 1 Association of sector and depression scores on demographic variables

\begin{tabular}{lllll}
\hline Effect & Wilks' lambda & F statistics & $\boldsymbol{p}$ value & Partial eta square \\
\hline Sector & 0.741 & 33.660 & $\mathbf{0 . 0 0 0}$ & 0.259 \\
Depression scores & 0.902 & 2.015 & $\mathbf{0 . 0 0 5}$ & 0.025 \\
Sector $\times$ age & 0.741 & 13.446 & $\mathbf{0 . 0 0 0}$ & 0.252 \\
Sector $\times$ gender & 0.741 & 0.048 & 0.827 & 0.000 \\
Sector $\times$ relationship status & 0.741 & 3.265 & 0.072 & 0.008 \\
Sector $\times$ ethnicity & 0.741 & 0.586 & 0.444 & 0.002 \\
Depression scores $\times$ age & 0.902 & 1.144 & 0.337 & 0.015 \\
Depression scores $\times$ gender & 0.902 & 5.159 & $\mathbf{0 . 0 0 0}$ & 0.062 \\
Depression scores $\times$ relationship status & 0.902 & 1.480 & 0.195 & 0.019 \\
Depression scores $\times$ ethnicity & 0.902 & 0.935 & 0.458 & 0.012
\end{tabular}

*Sector $=$ students and doctors

applied, and male doctor and students were found to have a significantly high association $(p=<0.001)$ with depression scores as compared to their counterpart and students. Overall depression scores were analysed, and it was found that students have higher depression scores as compared to doctors as shown in Fig. 1.

Another multivariate model was used to analyse the relationship between depressive symptoms and sectors as shown in Table 2. Positive association was observed among sector and symptom of hopelessness, sleep changes and appetite/weight changes. Further, when multiple one-way ANOVA was used, it was found out that previously mentioned symptoms were found more in students as compared to doctors.

In order to analyse association between depression scores and symptoms, chi-square was applied and it was found that all the symptoms were significantly associated with depressive scores with $p$ value of less than 0.001 . The most common symptom among both groups was sleep changes while the least common symptom among doctors was concentration problem and among students was feeling of helplessness as shown in Fig. 2.

Further, participants were asked regarding history of any recent trauma as shown in Fig. 3 and it was compared with depressive scores by using chi-square and significant association was found between depression scores and harassment, failure to solve the problem and social embarrassment with a $p$ value to less than 0.001 . It was also found that $26 \%$ of the students were having suicidal thoughts while only $16 \%$ of the doctors were having suicidal intentions.

\section{Discussion}

Depression is the disease following iceberg phenomenon as it is the most underscreened, underdiagnosed and undertreated one. Medical professionals either students or working doctors are equally at high risk of developing depressive symptoms [10]. However, students show a

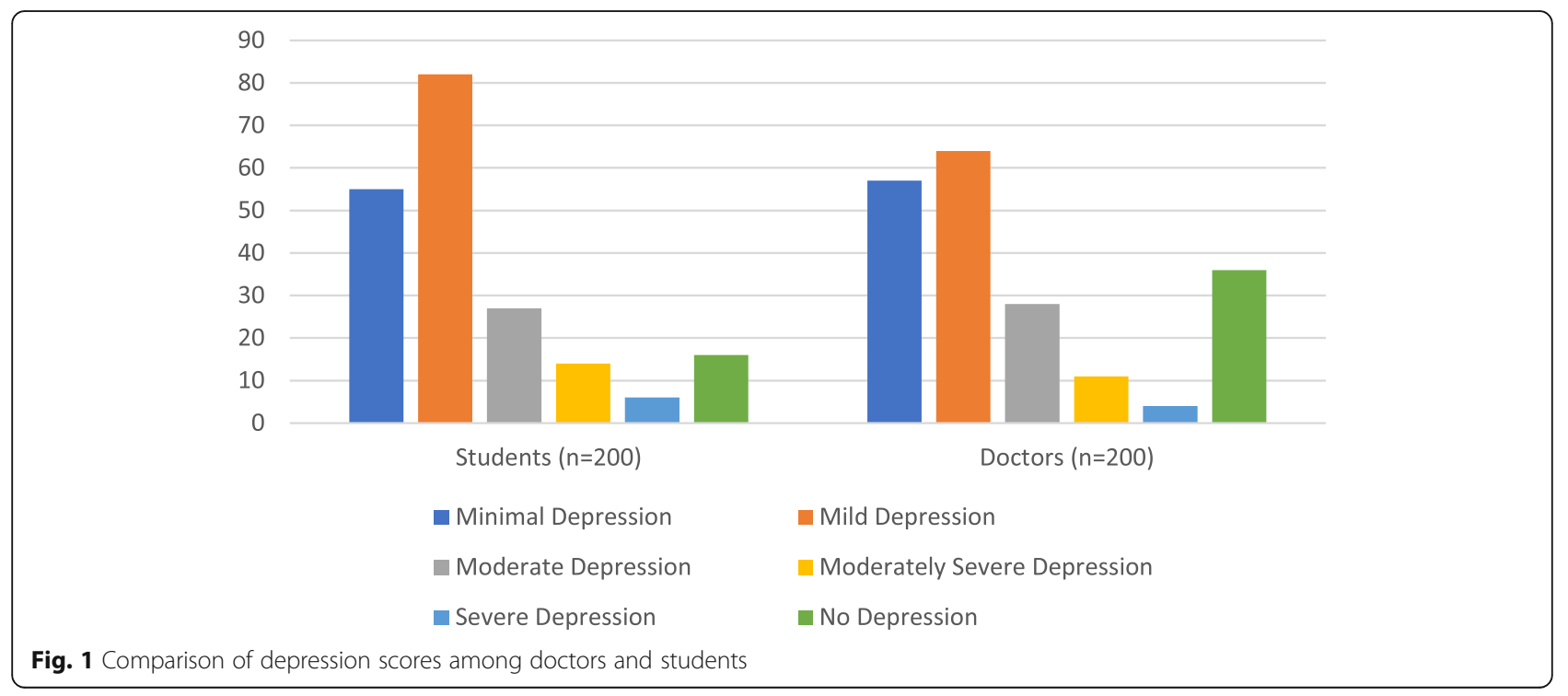


Table 2 Association of depressive symptoms with sectors

\begin{tabular}{lllll}
\hline Effect & Wilks' lambda & F statistics & $\boldsymbol{p}$ value & Partial eta square \\
\hline Sector & 0.966 & 1.909 & 0.067 & 0.034 \\
Depression scores & 0.413 & 10.742 & $\mathbf{0 . 0 0 0}$ & 0.162 \\
Sector $\times$ depression scores & 0.848 & 1.837 & $\mathbf{0 . 0 0 2}$ & 0.032 \\
Sector $\times$ thoughts of hurting yourself & 0.966 & 1.494 & 0.222 & 0.004 \\
Sector $\times$ helplessness & 0.966 & 1.168 & 0.280 & 0.003 \\
Sector $\times$ hopelessness & 0.966 & 6.402 & $\mathbf{0 . 0 1 2}$ & 0.016 \\
Sector $\times$ loss of interest & 0.966 & 1.762 & 0.185 & 0.005 \\
Sector $\times$ appetite or weight changes & 0.966 & 3.438 & 0.064 & 0.009 \\
Sector $\times$ sleep changes & 0.966 & 4.366 & $\mathbf{0 . 0 3 7}$ & 0.011 \\
Sector $\times$ unexplained aches & 0.966 & 0.535 & 0.465 & 0.001
\end{tabular}

*Sector $=$ students and doctors

higher percentage of depression than doctors as the current study reported about $41 \%$ of medical students were mildly depressed. Similar trends of depression are seen in other areas. For example, a study in Cape Town stated that $36.4 \%$ of medical students suffered from major depressive disorder [16]. Another study stated that $41.1 \%$ of medical students in the Middle East had positive depression screens [17]. This number highly resembles the results in our setup. However, if these results are compared to depression scores in doctors, then we see a smaller percentage of depression than in medical students. In the current setup, $32 \%$ of doctors showed mild depression. A cross-sectional study in Austria showed that $10.3 \%$ of physicians suffered from major depression [18]. This number is lower than current results, so depression may be a bigger issue in our setup. More importantly, the trend shows that physicians can also be depressed, but they are less depressed than medical students.

Certain lifestyle practices and risk factors seem to be similar contributors to depression in both students and physicians. One main factor, sleep, was considered a high statistical factor in current study. A study by Wang et al. stated that disruption in continuity and REM sleep correlates with episodes of depression in people [19]. Similarly, another study by Zhai et al. showed that short sleep durations have a significant association with depression [20]. These findings support our correlation of sleep to depression. A major difference in both populations of our setup is that medical students seem to have a hard time concentrating when depressed, whereas physicians seem to have appetite changes when they are depressed. The decrease in concentration could also be contributed by the lack of sleep. One article states that

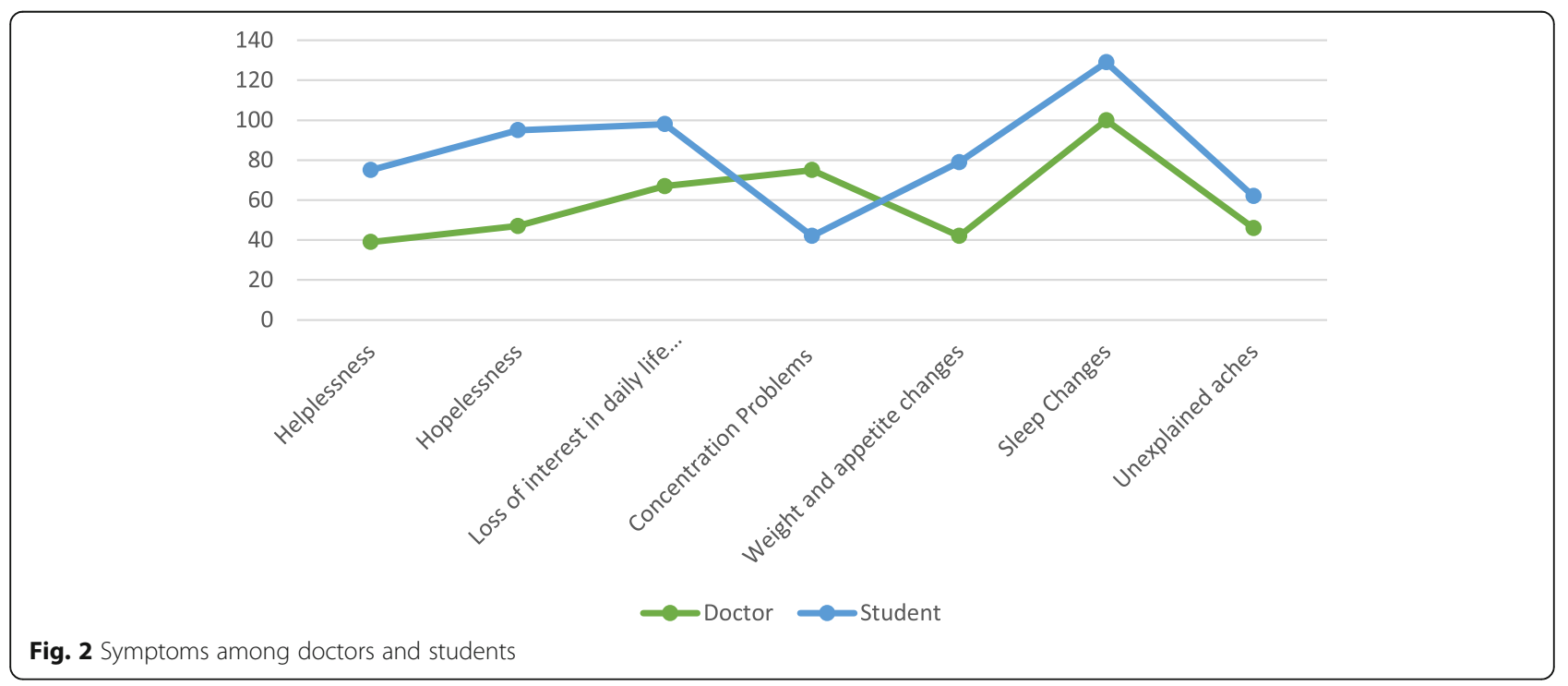




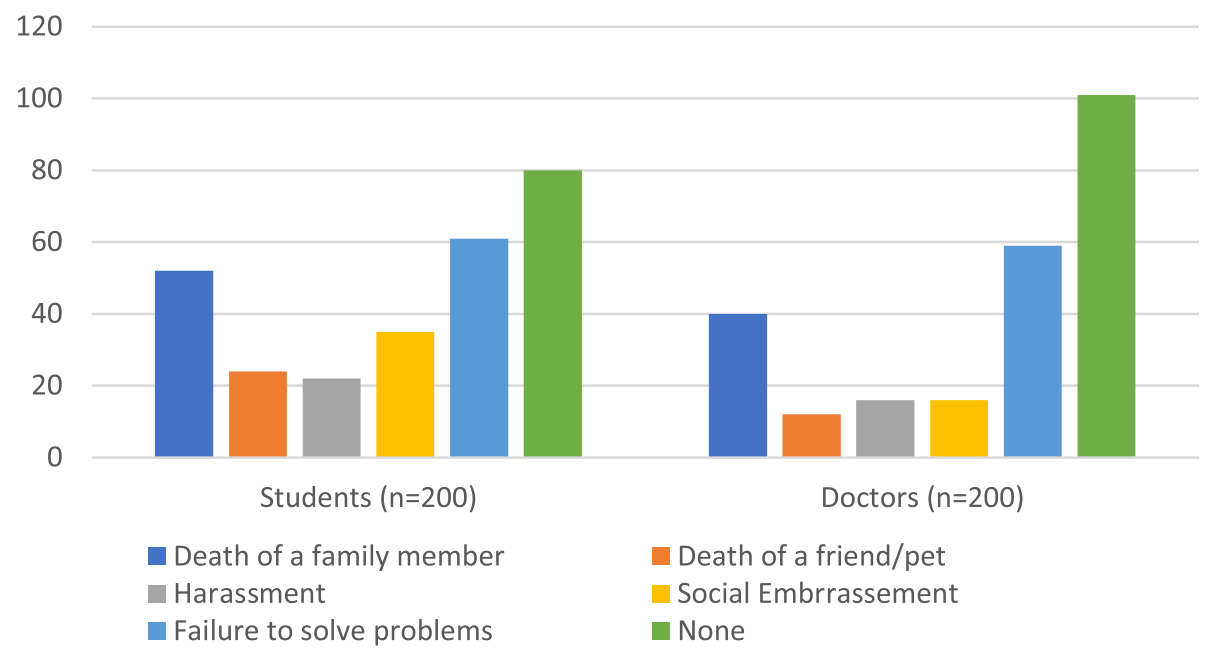

Fig. 3 History of recent trauma

lack of sleep causes slowing of response speed and lack of attention [21]. So we can assume that the lack of sleep is a contributor to concentration. Doctors may not have this problem because they have more experience than students. A study states that experience can have a profound effect on learning and consolidated memories [22]. In other words, the past experiences allow doctors to stay focused because they are already well versed in their fields.

Certain events of recent trauma also seem to show similar trends between medical students and physicians and were accessed through multiple questions. One of these events is failure to solve a problem. In the current setup, this was a factor in $29.5 \%$ of physicians and $30.5 \%$ of medical students. According to Kraines and Wells, depression was associated with rejection and social problem solving [23]. It cannot be pinpointed what kind of problems physicians or medical students struggle to resolve. This study indicates that medical students and physicians could be having a hard time dealing with social problems.

Physicians suffer from appetite changes more than students. Not much is known on this. One article states that appetite changes and depressive syndrome are highly associated with higher BMI [24]. A meta-analysis stated that overweight and health professional did not lead to a significant statistical finding [25]. This is true for the current setup as well. Appetite changes just seem to be a finding that differs between medical students and physicians. It is important to report any contrasts seen in data.

The current study showed that both medical students and doctors are depressed. Specific causes must be pointed out to pinpoint these issues in the general population. For example, if sleep changes seem to be the problem, then better work schedules need to be set up for higher productivity. However, more specific reasoning needs to be identified to have a clear picture on causes of depression. This study gives a slight insight on the contrast in depression symptoms such as concentration and appetite changes. Limitation of current study was focusing only the Karachi; a larger sample is needed to further expand the observation. Many are hesitant in the health business to talk about depression, so filling out surveys was tough from participants.

\section{Conclusion}

It is concluded that depression is highly prevalent among medical students when comparing with on-duty doctors, so they should be screened with regular intervals and good counselling sessions to prepare them for a good professional performance and generating a better health care system.

\section{Abbreviations}

NIMH: National Institute of Mental Health; PHQ 9: Public Health

Questionnaire; MANOVA: Multivariate analysis model; SPSS: Statistical Package for Social Sciences; DSM IV: The Diagnostic and Statistical Manual of Mental

Disorders, Fourth Edition; BMI: Body mass index

\section{Acknowledgements}

Not applicable.

\section{Authors' contributions}

MFHQ, DM and SS planned the basic framework for manuscript, conducted the analysis and improved the final version of manuscript. ZJA, UK, JD, NK, FKS and AH collected the data and prepared the initial manuscript. All authors have read and approved the manuscript.

\section{Funding}

Not applicable.

\section{Availability of data and materials}

The datasets used and analysed during the current study are available from the corresponding author on reasonable request. 


\section{Ethics approval and consent to participate}

The study was approved by the ethical review board of Ziauddin University (Reference Number\# SS002018). Written informed consent and confidentiality of research data were ensured.

\section{Consent for publication}

Not applicable.

\section{Competing interests}

The authors declare that they have no competing interests.

\section{Author details}

'Ziauddin University, 4/B Shahra e Ghalib, Block 6, Clifton, Karachi, Pakistan. ${ }^{2}$ Department of Physiology, CMH Institute of Medical Sciences, Bahawalpur, Pakistan

Received: 26 August 2020 Accepted: 15 October 2020

Published online: 30 October 2020

\section{References}

1. Marcus M, Yasamy MT, van Ommeren MV, Chisholm D, Saxena S (2012) Depression: a global public health concern

2. Mikolajczyk RT, Maxwell AE, El Ansari W, Naydenova V, Stock C, llieva S, Dudziak U, Nagyova I (2008) Prevalence of depressive symptoms in university students from Germany, Denmark, Poland and Bulgaria. Soc Psychiatry Psychiatr Epidemiol 43:105-112

3. Sarokhani D, Delpisheh A, Veisani Y, et al (2013) Prevalence of Depression among University Students: A Systematic Review and Meta-Analysis Study. Depression Research and Treatment 2013:373-387. https://doi.org/10.1155/ 2013/373857.

4. Rotenstein LS, Ramos MA, Torre M, Segal JB, Peluso MJ, Guille C, Sen S, Mata DA (2016) Prevalence of depression, depressive symptoms, and suicidal ideation among medical students: a systematic review and metaanalysis. Jama 316:2214-2236

5. Jadoon NA, Yaqoob R, Raza A, Shehzad MA, Zeshan SC (2010) Anxiety and depression among medical students: a cross-sectional study. J Pak Med Assoc 60:699-702

6. Khan MS, Mahmood S, Badshah A, Ali SU, Jamal Y (2006) Prevalence of depression, anxiety and their associated factors among medical students in Karachi, Pakistan. J Pak Med Assoc 56:583

7. Alvi T, Assad F, Ramzan M, Khan FA (2010) Depression, anxiety and their associated factors among medical students. J Coll Physicians Surg Pak 20: 122-126

8. Qureshi MF, Sadiq S, Mohammad D, et al (2019) Does sector matter in House Officers performances?; A Cross sectional study. 81-90. https://doi. org/10.15694/mep.2019.000135.1.

9. Kaneita Y, Ohida T, Uchiyama M, et al (2006) The relationship between depression and sleep disturbances: a Japanese nationwide general population survey. J Clin Psych 67:196-203. https://doi.org/10.4088/jcp. v67n0204. Accessed 29 Mar 2006.. Accessed 29 Mar 2006.

10. Wang J-N, Sun W, Chi T-S, Wu H, Wang L (2010) Prevalence and associated factors of depressive symptoms among Chinese doctors: a cross-sectional survey. Int Arch Occup Environ Health 83:905-911

11. Wada K, Yoshikawa T, Goto T, Hirai A, Matsushima E, Nakashima Y, Akaho R, Kido M, Hosaka T (2011) Association of depression and suicidal ideation with unreasonable patient demands and complaints among Japanese physicians: a national cross-sectional survey. Int J Behav Med 18:384-390

12. Nakada A, Iwasaki S, Kanchika M, et al (2016) Relationship between depressive symptoms and perceived individual level occupational stress among Japanese schoolteachers. Ind Health 54:396-402. https://doi.org/10. 2486/indhealth.2015-0195.

13. Atif K, Khan HU, Ullah MZ, Shah FS, Latif A (2016) Prevalence of anxiety and depression among doctors; the unscreened and undiagnosed clientele in Lahore, Pakistan. Pak J Med Sci 32:294

14. Zhang YL, Liang W, Chen ZM, Zhang HM, Zhang JH, Weng XQ, Yang SC, Zhang L, Shen LJ, Zhang YL (2013) Validity and reliability of Patient Health Questionnaire-9 and Patient Health Questionnaire-2 to screen for depression among college students in China. Asia Pac Psychiatry 5:268-275

15. Cameron IM, Crawford JR, Lawton K, Reid IC (2008) Psychometric comparison of PHQ-9 and HADS for measuring depression severity in primary care. Br J Gen Pract 58:32-36
16. Van der Walt S, Mabaso WS, Davids EL, De Vries PJ (2019) The burden of depression and anxiety among medical students in South Africa: a crosssectional survey at the University of Cape Town. S Afr Med J 110:69-76

17. Gold JA, Hu X, Huang G, Li WZ, Wu YF, Gao S, Liu ZN, Trockel M, Li WZ, Wu YF, Gao S, Liu ZN, Rohrbaugh RM, Wilkins KM (2019) Medical student depression and its correlates across three international medical schools. World J Psychiatry 9:65-77

18. Wurm W, Vogel K, Holl A, Ebner C, Bayer D, Morkl S, Szilagyi IS, Hotter E, Kapfhammer HP, Hofmann P (2016) Depression-burnout overlap in physicians. PLoS One 11:e0149913

19. Wang YQ, Li R, Zhang MQ, Zhang Z, Qu WM, Huang ZL (2015) The neurobiological mechanisms and treatments of REM sleep disturbances in depression. Curr Neuropharmacol 13:543-553

20. Zhai L, Zhang H, Zhang D (2015) Sleep duration and depression among adults: a meta-analysis of prospective studies. Depress Anxiety 32:664-670

21. Killgore WD (2010) Effects of sleep deprivation on cognition. Prog Brain Res 185:105-129

22. Parsons RG (2018) Behavioral and neural mechanisms by which prior experience impacts subsequent learning. Neurobiol Learn Mem 154:22-29

23. Kraines MA, Wells TT (2017) Rejection sensitivity and depression: indirect effects through problem solving. Psychiatry 80:55-63

24. Baldofski S, Mauche N, Dogan-Sander E, Bot M, Brouwer IA, Paans NPG, Cabout M, Gili M, van Grootheest G, Hegerl U, Owens M, Roca M, Visser M, Watkins E, Penninx B, Kohls E (2019) Depressive symptom clusters in relation to body weight status: results from two large European multicenter studies. Front Psychiatry 10:858

25. Saulle R, Bernardi M, Chiarini M, Backhaus I, La Torre G (2018) Shift work overweight and obesity in health professionals: a systematic review and meta-analysis. Clin Ter 169:e189-e197

\section{Publisher's Note}

Springer Nature remains neutral with regard to jurisdictional claims in published maps and institutional affiliations.

\section{Submit your manuscript to a SpringerOpen ${ }^{\circ}$ journal and benefit from:}

- Convenient online submission

- Rigorous peer review

- Open access: articles freely available online

- High visibility within the field

- Retaining the copyright to your article

Submit your next manuscript at $>$ springeropen.com 